\title{
Exits from unemployment: Recall or new job ${ }^{\text {is }}$
}

\author{
Alfonso Alba-Ramírez ${ }^{\mathrm{a}}$, José M. Arranz ${ }^{\mathrm{b}}$, Fernando Muñoz-Bullón \\ a Universidad Carlos III de Madrid, Departamento de Economí, C/Madrid, 126. 28903 Getafe, Madrid, Spain \\ b Universidad de Alcalá, Departamento de Estadística, Estructura Económica y OEI, Plaza de la Victoria 3 , \\ 28803 Alcalá de Henares, Madrid, Spain \\ c Universidad Carlos III de Madrid, Sección de Organización de Empresas, \\ C/Madrid, 126. 28903 Getafe, Madrid, Spain
}

\begin{abstract}
This paper studies transitions out of unemployment in Spain distinguishing between recall to the same employer and reemployment in a new job. We use a large sample of newly unemployed workers obtained from Social Security records for Spain. These data contain information about each individual's employer identity before and after the unemployment spell. A discrete time duration model with competing risks of exits serves us to investigate the factors that influence the probabilities of leaving unemployment to return to the same employer or to find a new job with a different employer. We find that taking into account the route to exit unemployment helps us to understand the influence of individual and job characteristics on the hazard rate. Moreover, the recall hazard rate exhibits no duration dependence, whereas the new job hazard rate presents positive duration dependence.
\end{abstract}

JEL classification: $\mathrm{J} 21 ; \mathrm{J} 24$

Keywords: Discrete-time duration model; Unobserved heterogeneity; Re-employment probabilities; Recall hazard; Newjob hazard

\footnotetext{
We would like to thank two anonymous referees and the co-editor of Labour Economics, Fabien Postel-Vinay, for their helpful comments and suggestions. We have also benefited from comments made by Gerard Van den Berg, Ralf Wilke, Joachim Wolff, and seminar participants at the International Workshop "European Unemployment: Recent Developments in Duration Analysis Using Register Data" held at ZEW, Mannheim (Germany, October, 2004), and the II World Conference Society of Labour Economists and the European Association of Labour Economics (San Francisco, 2005). We are very grateful to the Spanish Ministry of Labour and Social Affairs for financial support and the data used. Financial support was also provided by the Ministry of Education and Science, project SEC2003-08714. Only the authors are responsible for any errors.

* Corresponding author.

E-mail addresses: alfonso.alba@uc3m.es (A. Alba-Ramírez), josem.arranz@uah.es (J.M. Arranz), fernando.munoz@uc3m.es (F. Muñoz-Bullón).
} 


\section{Introduction}

Workers who lose their jobs can become re-employed either by being recalled to their previous employers or by finding new jobs. Temporary layoff unemployment can be defined as unemployment spells that end with the unemployed person being rehired by the same employer. Around one-third of unemployed workers have been estimated to be on temporary layoff in the United States and Canada (OECD, 2002, pp. 218). ${ }^{1}$ Although underestimated by previous studies, ${ }^{2}$ recent work has found temporary layoff to be prevalent also in Europe. Of all terminations of unemployment spells, temporary layoffs have been estimated to account for more than a third in Austria (Winter-Ebmer, 1998), Norway (Røed and Nordberg, 2003), and Denmark (Jensen and Svarer, 2003). For Germany, Mavromaras and Rudolph (1998) show that temporary layoffs account for $17 \%$ of jobs started by benefit recipients. Much less evidence exists for the presence of temporary layoffs in Spain. The possibility of exiting unemployment through recall has been ignored in the analysis of employment transitions in Spain, mainly due to lack of adequate data.

Against this background, one of the motivations of this paper is to document that recall by the previous employer is a relevant outcome for transitions out of unemployment in Spain. In our data set, more than a third of unemployed who find a job return to the previous employer. This finding needs to be considered in a context in which more than a third of workers hold fixed-term contracts. When a fixed-term contract ends and a job separation occurs, an implicit agreement between the worker and the employer may lead to recall. In principle, neither part is committed to re-initiate the employment relation at a future date. However, absence of experience rating in the unemployment insurance system can create incentives for employers to offer fixed-term instead of permanent contracts, as the end of the contract gives the employer employment flexibility and leaves open the possibility of future recall.

A second motivation for the present study is to contribute to the literature exploring the driving forces behind the duration pattern of recall unemployment spells. As compared to the large body of empirical work on labour market outcomes of searching for a new job, there are fewer studies addressing the outcome of return to the previous employer. Once its empirical prevalence has been assessed, temporary layoff can be approached from two theoretical perspectives. ${ }^{3}$ One follows the implicit contract theory (Feldstein, 1976, 1978; Baily, 1977); the other is based on the job search theory (Mortensen, 1990). In the implicit contract theory, firm's incentives play a key role in the intensity and timing of recalls, since they tend to layoff workers on temporary bases in response to a decline in product demand. Therefore, temporary layoffs result from fluctuations of the demand for the product, and reflect high attachment of the worker to the firm.

In the job search theory, search effort is predicted to be smaller among workers on temporary layoff than among other unemployed workers. Given that a worker's productivity tends to decline with time

\footnotetext{
${ }^{1}$ Previous studies also found strong evidence of temporary layoff in Canada and the USA. Robertson (1989) documents that more than $50 \%$ of total unemployment spells in Canada are terminated because the worker returns to the previous employer; and Katz and Meyer (1990) report that 57\% of all unemployment spells in their data sample from Missouri and Pennsylvania (USA) are temporary layoffs.

${ }^{2}$ Earlier studies have suggested that tighter regulatory impediments to the recruitment and dismissal of employees were responsible for a lower incidence of temporary layoff in Europe (e.g., Moy and Sorrentino, 1981; Gutierrez-Rieger and Podzeczeck, 1981; for legal restraints on layoff in general, see Emerson, 1988).

${ }^{3}$ These two approaches are compatible with many other conditions that provide incentives for firms to layoff workers temporarily: 1) An imperfectly experience-rated unemployment insurance system; 2) Workers' possession of specific human capital and its high cost of acquisition; 3) The difficulties and costs associated with recruitment in the open market; 4) Uncertainties about the quality of the job match that will be achieved with newly recruited employees, etc.
} 
out of work, a likely search strategy for a worker that expects to be recalled is to reduce recall waiting and put more effort into searching for a new job as unemployment duration lengthens. This behavior is consistent with the finding of significant differences between the effects of the explanatory variables on the recall hazard rate and the new job hazard rate (Corak, 1996; Katz, 1986; Jensen and WestergärdNielsen, 1990; Jensen and Nielsen, 1999; Rosholm and Svarer, 2001; Røed and Nordberg, 2003).

In this article, we use a discrete-time duration model with competing risks of exits to investigate the observed and unobserved factors that influence the probabilities of leaving unemployment to return to the same employer or to find a new job with a different employer. We focus on involuntary, firm-initiated job separations. By considering these two alternatives for exiting unemployment, we are able to shed new light on the determinants of transitions from unemployment to employment in Spain. In addition, we make an empirical contribution to the growing literature that shares the methodology of distinguishing two alternative routes for leaving unemployment. The database used comes from Social Security records, and contains information on all employment (and unemployment) spells of workers in the Spanish labour market over a three-year period -from June 1999 to June 2002.

We obtain numerous empirical results which are consistent with those of previous studies for other countries. We find that recall and new job outcomes are associated with different individual and job characteristics. In particular, as unemployment duration lengthens, the new job finding hazard rate remains relatively high, while the recall hazard rate falls and becomes minuscule. This result suggests that, as workers become less confident about being recalled by the previous employer, they increase their search for a new job, which turns out to be their route for escaping unemployment (Katz and Meyer, 1990). Another possible interpretation of this result could be based on the nature of the implicit agreement between the firm and the worker to reinitiate the employment relationship after some time has passed. Among recalled workers, we do not observe too long periods of separations because neither side is interested in risking acquired specific human capital, which is so valuable to the firm.

The rest of this paper is organised as follows. Section two describes the data and the sample. In Section 3, we specify the discrete-time hazard model with competing risks for modelling the transitions from unemployment to employment through recall or a different employer. Section 4 provides the estimation results. Finally, some concluding remarks are presented in the last section.

\section{The data and sample}

This paper uses data from Social Security records that contain information on all employment (and non-employment) spells of workers in the Spanish labour market from June 1999 to June 2002. The data set includes information on age, gender, qualification level, ${ }^{4}$ dates of start and end of employment spells, reason for termination of the spell (voluntary/involuntary or retirement), province of residence of the worker, an identifier of whether each employment spell is accomplished through a temporary help agency (THA) or not, the type of contract held by the worker (temporary or permanent), and firm size. This data set was matched with HSIPRE (Histórico del Sistema Integrado de Prestaciones), another administrative data set that provides

\footnotetext{
${ }^{4}$ The qualification level indicates a position in a ranking determined by the worker's contribution to the Social Security system. It is somewhat related to the individual's qualification level, since it reflects the worker's professional category and salary. It could happen, however, that a worker with higher education is far below the category that would correspond to his formal education (see appendix Table A.1).
} 
information on the last ten spells of unemployment benefits received by each worker. ${ }^{5}$ Thus, we know whether each individual was receiving unemployment benefits when out of work, the type of benefits received (of contributory or assistance type), the number of days granted for benefit and the number of days of benefit receipt.

The advantage of using Social Security records for the analysis of flows in and out of unemployment is threefold: (i) The availability of information on all jobs held by the individual during a certain interval of time; (ii) unemployment duration is very accurate and detailed; (iii) it is possible to distinguish spells ending through recall from those ending through the finding of a new job. In addition, the combination with data from the unemployment benefits receipt allows us to overcome many of the limitations of studies that use data from either Social Security records or the HSIPRE. ${ }^{6}$ An advantage of the dataset is that information is available on the entire spell of non-employment, and a limitation is that it contains the complete work history of individuals over a rather short period (from June 1999 to June 2002).

Since each establishment is given its identification code in each province it operates, our database contains an anonymous identification number for the employer associated with every single spell of employment. Thus, temporary separations are identified by whether or not each firm's identification numbers of two subsequent employment spells coincide. It is noteworthy that we only refer to temporary layoffs in an ex post sense - i.e., job separations ending in recall. We have no information on ex ante temporary layoffs -i.e., those that begin with a person expecting to be recalled. Thus, the ex post measure is likely to underestimate the total amount of unemployment affected by recall prospects, since it does not include the unemployment of those who initially waited for recall but were not recalled. In any case, this ex post concept gives the proportion of unemployment from spells involving no job change (Feldstein, 1975; Clark and Summers, 1979), and it is not ambiguous in the sense that it is not based on whether individuals decided what is a new employer and what is not. ${ }^{7}$

The data contains an initial sample of 79,267 representative cases drawn from workers who were subject to Social Security contributions and become jobless at some point in time during the first semester of 2000. We drop individuals who do not meet all the following criteria: 1) Entered unemployment due to involuntary reasons -i.e., dismissals or termination of temporary contracts. ${ }^{8}$ As we consider only the first spell of unemployment occurring in the indicated period,

\footnotetext{
${ }^{5}$ Therefore, our data is composed of two different random samples for the Spanish labour market: (i) $2.5 \%$ of individuals who were either employed or receiving unemployment insurance benefits in June of 2002; (ii) $2.5 \%$ of individuals who were registered at the employment office in June of 2002 without receiving any unemployment benefits. This second sample was extracted in order not to exclude from our analysis the individuals who did not appear at the time of selecting the sample (June of 2002) from Social Security records.

${ }^{6}$ A different extraction from Social Security records was previously used to study employment and unemployment spells through the use of duration models in García-Fontes and Hopenhayn (1996), García-Pérez (1997), and GarcíaPérez and Muñoz-Bullón (2005a,b), but they only have data up to the year 1999. On the other hand, Cebrián et al. (1996), Arranz and Muro (2004) and Jenkins and García-Serrano (2004) have used HSIPRE.

${ }^{7}$ The wide use of temporary employment in the Spanish labour market advises us against the use of the term "temporary layoff" in connection with recall activity by firms. For this reason, we analyse unemployment duration paying more attention on how the unemployment spell ends than on how it was initiated. More specifically, a great majority of workers in Spain become unemployed because of end of their contracts. We understand that end of contract is not exactly the same thing as layoff. By contracting with fixed-term contracts, firms have no need for temporary layoffs. Workers with permanent contracts are expensive to dismiss, so when they are laid-off they are unlikely to come back or to be called back. Because of these considerations, when we use the term layoff it has to be understood that separations because of expiration of contracts are also included.

${ }^{8}$ We cannot distinguish between these two reasons for job termination. Workers who quit their jobs (end their employment for voluntary reasons) are not considered in this study because we do not know why this happens and these workers are likely to leave the labour force (see García-Pérez and Muñoz-Bullón, 2005b).
} 
we obtain a "flow sample" of unemployed workers in the terminology of Lancaster (1990), pp. $162 ; 2)$ In the previous job, the individual was registered with the General System of Social Security ${ }^{9}$; 3) We have complete information on all the variables used in the empirical analysis; 4) Workers must remain out of work for more than 30 days. We eliminate workers with unemployment spells lasting 30 days or less because they experiment straight movements from job to job without experiencing unemployment. Finally, we limit our sample to workers aged between 16 and 62 (to avoid complications associated with early retirement).

After applying the indicated sample selections, we obtain a final sample of 23,035 individuals. Table A.2 of the Appendix shows the loss of observations from the initial dataset. In the sample, each of those individuals has been followed from the date when they become unemployed in the first semester of the year 2000 until their re-employment occurs. Those still without a job in June 2002 have been treated as right-censored observations. ${ }^{10}$ Main variable definitions and basic descriptive statistics for the sample used in the empirical analysis are given in Table 1 .

As it is shown in Table 1, 36\% of unemployed who find a job return to the firm where they were previously employed (8,277 over 23,035 individuals). Therefore, recalls do constitute, indeed, an important element of unemployment in Spain. This figure is even higher than the one found in other European countries. ${ }^{11}$ We also see that recall is more concentrated on certain individuals. In particular, males are less likely to return to their previous employer when exiting from unemployment (66 percent of recalled individuals are women as opposed to 44 percent among non-recalled individuals). Moreover, age appears as another relevant determinant of being recalled: the recall outcome is slightly more important for individuals aged 35 and over. And individuals in possession of either low or low-intermediate qualification levels tend to experiment a relatively higher recall outcome. Moreover, on average, recalls seem to be more concentrated on workers with shorter unemployment spells, shorter employment duration and slightly higher number of previous jobs. ${ }^{12}$

According to the results from a multivariate logit model ${ }^{13}$ (not shown) the probability that a given unemployed person becomes recalled to his or her previous employer, rather than becoming employed in a new job, is more likely to be associated with the following characteristics: women, older than 39 - a fact which is consistent with the view of firms trying to maintain their eldest employees' specific human capital - either high or low skilled - although this effect of qualification only remains significant for men-, held a non permanent contract, worked in a relatively short period of time in firms with more than 200 employees, spent less time

\footnotetext{
${ }^{9}$ Because specific regimes like Farming and Self-employment have different rules for accessing benefits and the peculiarities of their employment relationships, they should be object of separate analysis.

${ }^{10}$ We have also created an artificial right censoring for observations of workers whose unemployment spell duration extends beyond 19 months.

11 For instance, Germany see Mavromaras and Rudolph (1998) or Mavromaras and Orme (2004).

12 In addition, cross tabulations of various individual characteristics with these data not shown, but available from the authors upon request- clearly show that exit from unemployment through recall is particularly high for low skilled women (48.2\%) and for women 55 and older (70.8\%). Unemployment duration is negatively related to recall intensity: $21.5 \%$ of women unemployed for more than a year as compared with $48.3 \%$ of women unemployed for less than 20 weeks are recalled. Finally, recall tends to be more common among individuals in the tails of the qualification distribution.

13 Distinguishing between workers who found a new job and workers who were recalled, we performed a logit regression for the entire sample and by gender. The personal characteristics used as independent variables were gender, age, qualification level, the type of contract in the previous job, the number of employees in the previous employer, tenure in the previous job, unemployment duration, whether or not the previous employer was a temporary help agency, whether or not the individual receive unemployment benefits (either contributory or assistance), the number of previous jobs, and the regional unemployment rate.
} 
Table 1

Main descriptive statistics for first unemployment spell in 2000

\begin{tabular}{|c|c|c|c|c|}
\hline Variable & Description & $\begin{array}{l}\text { Entire sample } \\
\text { Mean (S.D.) }\end{array}$ & $\begin{array}{l}\text { Recall } \\
\text { Mean (S.D.) }\end{array}$ & $\begin{array}{l}\text { New Job } \\
\text { Mean (S.D.) }\end{array}$ \\
\hline Gender & 1 if male & 0.517 & 0.436 & 0.562 \\
\hline Age & Age in years when entering unemployment & & & \\
\hline 16-19 & 1 if aged 16 to 19 & 0.071 & 0.043 & 0.087 \\
\hline $20-24$ & 1 if aged 20 to 24 & 0.218 & 0.166 & 0.246 \\
\hline $25-29$ & 1 if aged 25 to 29 & 0.206 & 0.176 & 0.223 \\
\hline $30-34$ & 1 if aged 30 to 34 & 0.152 & 0.158 & 0.149 \\
\hline $35-39$ & 1 if aged 35 to 39 & 0.122 & 0.147 & 0.109 \\
\hline $40-44$ & 1 if aged 40 to 44 & 0.092 & 0.122 & 0.076 \\
\hline $45-49$ & 1 if aged 45 to 49 & 0.064 & 0.086 & 0.052 \\
\hline $50-54$ & 1 if aged 50 to 54 & 0.046 & 0.061 & 0.037 \\
\hline $55-59$ & 1 if aged 55 to 59 & 0.023 & 0.032 & 0.019 \\
\hline $59-62$ & 1 if aged more than 59 years old & 0.005 & 0.009 & 0.003 \\
\hline \multicolumn{5}{|l|}{ Qualification level(*) } \\
\hline High & $\begin{array}{l}1 \text { if Social Security bracket for } \\
\text { contribution in previous job is } 1,2 \text { or } 3 \text {. }\end{array}$ & 0.083 & 0.099 & 0.073 \\
\hline Upper-intermediate & $\begin{array}{l}1 \text { if Social Security bracket for } \\
\text { contribution in previous job is } 4,5 \text { or } 6\end{array}$ & 0.111 & 0.097 & 0.119 \\
\hline Lower-intermediate & $\begin{array}{l}1 \text { if Social Security bracket for } \\
\text { contribution in previous job is } 7 \text { or } 8\end{array}$ & 0.289 & 0.244 & 0.314 \\
\hline Low & $\begin{array}{l}1 \text { if Social Security bracket for } \\
\text { contribution in previous job is } 9 \text { or } 10\end{array}$ & 0.517 & 0.559 & 0.494 \\
\hline Type of contract & Type of contract in previous job & & & \\
\hline Permanent & 1 if permanent contract & 0.069 & 0.029 & 0.091 \\
\hline Permanent per task & 1 if permanent per task contract & 0.036 & 0.084 & 0.012 \\
\hline Temporary & 1 if temporary contract & 0.849 & 0.825 & 0.863 \\
\hline Other contract type & 1 if other contract type & 0.044 & 0.062 & 0.034 \\
\hline Temporary help agency & 1 if previously employed through a THA & 0.052 & 0.036 & 0.061 \\
\hline \multicolumn{5}{|l|}{ Firm size } \\
\hline$<10$ employees & 1 if number of employees up to 10 & 0.343 & 0.290 & 0.372 \\
\hline$>10$ and $<50$ & $\begin{array}{l}1 \text { if number of employees } \\
\text { above } 10 \text { and up to } 50\end{array}$ & 0.294 & 0.297 & 0.293 \\
\hline$>50$ and $<200$ & $\begin{array}{l}1 \text { if number of employees } \\
\text { above } 50 \text { and up to } 200\end{array}$ & 0.186 & 0.200 & 0.179 \\
\hline$>200$ and $<1000$ & $\begin{array}{l}1 \text { if number of employees } \\
\text { above } 200 \text { and up to } 1000\end{array}$ & 0.120 & 0.135 & 0.111 \\
\hline$>1000$ & 1 if number of employees above 1000 & 0.057 & 0.077 & 0.045 \\
\hline Tenure in previous job & Tenure in previous job (in weeks) & $\begin{array}{l}32.788 \\
(80.555)\end{array}$ & $\begin{array}{l}23.130 \\
(32.611)\end{array}$ & $\begin{array}{l}38.154 \\
(97.073)\end{array}$ \\
\hline$<4$ & 1 if up to 4 weeks & 0.255 & 0.298 & 0.232 \\
\hline$>4$ and $<20$ & 1 if above 4 weeks and up to 20 weeks & 0.308 & 0.273 & 0.327 \\
\hline$>20$ and $<1$ year & 1 if above 20 weeks and up to 1 year & 0.311 & 0.356 & 0.286 \\
\hline$>1$ and $<2$ years & 1 if above 1 year and up to 2 years & 0.076 & 0.051 & 0.090 \\
\hline$>2$ years & 1 if above 2 years & 0.049 & 0.021 & 0.064 \\
\hline $\begin{array}{l}\text { Worked in a Temporary } \\
\text { Help Agency }\end{array}$ & 1 if worked in a THA in previous job & 0.052 & 0.036 & 0.061 \\
\hline \multicolumn{5}{|c|}{ Unemployment benefit status } \\
\hline Contributory benefit & $\begin{array}{l}\text { Proportion collecting contributory benefits } \\
\text { at the beginning of spell ( } 1 \text { for each month } \\
\text { worker collects benefits) }\end{array}$ & 0.2230 & 0.1718 & 0.2515 \\
\hline
\end{tabular}


Table 1 (continued)

\begin{tabular}{|c|c|c|c|c|}
\hline Variable & Description & $\begin{array}{l}\text { Entire sample } \\
\text { Mean (S.D.) }\end{array}$ & $\begin{array}{l}\text { Recall } \\
\text { Mean (S.D.) }\end{array}$ & $\begin{array}{l}\text { New Job } \\
\text { Mean (S.D.) }\end{array}$ \\
\hline Assistance benefit & $\begin{array}{l}\text { Proportion collecting assistance } \\
\text { benefits at the beginning of spell } \\
\text { ( } 1 \text { for each month worker collects benefits) }\end{array}$ & 0.0538 & 0.0524 & 0.0546 \\
\hline Without benefit & $\begin{array}{l}\text { Proportion without benefits at the beginning } \\
\text { of spell ( } 1 \text { for each month worker collects } \\
\text { no benefits) }\end{array}$ & 0.7232 & 0.7759 & 0.6939 \\
\hline $\begin{array}{l}\text { Number of previous } \\
\text { jobs }\end{array}$ & Number of jobs held from June 1999 to actual job & $\begin{array}{l}2.111 \\
(1.740)\end{array}$ & $\begin{array}{l}2.266 \\
(1.860)\end{array}$ & $\begin{array}{l}2.026 \\
(1.663)\end{array}$ \\
\hline $\begin{array}{l}\text { Unemployment } \\
\text { duration }\end{array}$ & Duration in unemployment (in weeks) & $\begin{array}{l}25.853 \\
(22.154)\end{array}$ & $\begin{array}{l}22.264 \\
(19.782)\end{array}$ & $\begin{array}{l}27.846 \\
(23.129)\end{array}$ \\
\hline$>4$ and $<20$ & 1 if Above 4 weeks and up to 20 weeks & 0.577 & 0.652 & 0.535 \\
\hline$>20$ and $<1$ year & 1 if Above 20 weeks and up to 1 year & 0.281 & 0.251 & 0.298 \\
\hline$>1$ year & 1 if Above 1 year & 0.142 & 0.097 & 0.167 \\
\hline \multicolumn{5}{|l|}{ Sector of activity: } \\
\hline Industry & 1 if previous employment in industry & 0.132 & 0.135 & 0.130 \\
\hline Agriculture & 1 if previous employment in agriculture & 0.005 & 0.005 & 0.005 \\
\hline Construction & 1 if previous employment in construction & 0.165 & 0.147 & 0.175 \\
\hline Services & 1 if previous employment in services & 0.698 & 0.713 & 0.689 \\
\hline Sample size & & 23,035 & 8,227 & 14,808 \\
\hline
\end{tabular}

Notes: (*) See Appendix for the exact meaning of each of the 10 category contribution groups. We must underscore that the ten professional categories of worker contribution to Social Security in the database do not reveal the workers' level of qualification, but rather the required level of qualification for the job. For instance, an individual working in the lowest category, "labourers", may well be in possession of an academic degree. As in previous studies using data from the Social Security records, we group those eleven categories into four groups (see García-Pérez and Muñoz-Bullón, 2005a,b).

unemployed, received unemployment benefits of shorter duration and experienced more job changes.

\section{Econometric approach: a competing risks duration analysis}

For the empirical analysis, we specify a discrete-time duration model with competing risks of exits following the formulation proposed by Allison (1982). This same econometric framework has been used by Jenkins (1995), Alba-Ramirez (1998), Steiner (2001), Lauer (2003), and D' Addio and Rosholm (2005), among others. This type of models is common in the analysis of temporary layoffs where all the unemployed are subject to the competing risks of a recall and a new job (Katz, 1986; Røed and Nordberg, 2003) ${ }^{14}$ An advantage of the competing risks model is that we can obtain a neat result for the re-employment probability because we estimate the discrete-time hazard model simultaneously for the two kinds of exists from unemployment.

In a discrete-time duration model with competing risks, an individual's unemployment spell is represented by a random variable $T$, which can take on positive integer values only. We observe a total of $n$ independent individuals $(I=1, \ldots, n)$ beginning at some natural starting point $\mathrm{t}=1$. In the data used in

\footnotetext{
${ }^{14}$ A problem when estimating single risk duration models is the potential aggregation bias. Unemployed typically leave unemployment for different reasons (competing risks). Restricting the estimated coefficients for the baseline hazard and the covariates to be the same for all destination states might therefore be a very restrictive assumption. Therefore, the econometric model for the sequence of discrete choice models is a multinomial logit model or competing risks model; in each spell, the unemployed can either stay in unemployment (the reference category), be re-employed though a different employer or be re-employed though the same employer.
} 
this paper, such point is the month when the worker becomes unemployed for the first time during the first semester of the year 2000. Each observation continues until time $t$, at which point an event occurs or the observation is censored. The unemployment spell can end, $T=t$, in any of $j$ states: $j=1$ (reemployment through a new job) or $j=2$ (re-employment through the same employer as the immediately previous one; that is, a recall takes place). The observation is censored when the surviving individual is observed at month $t$ but not at month $t+1$. It is assumed that the time of censoring is independent of the hazard rate for the occurrence of events, at least after controlling for other factors. Also, it is assumed that the set of two states at which unemployment spells end is absorbing and equal for each person.

For modelling the transition from unemployment to employment through recall or a different employer, we define the discrete hazard rate. For the $i$ th person, the hazard rate into state $j$ $(j=1,2)$ in period $t, h_{i j}(t)$, is the conditional probability of a transition to state $j$ in this period, given that individual $i$ has been unemployed until $t .^{15}$

$$
h_{i j}(t)=\operatorname{Pr}\left[T_{i}=t_{i}, J=j \mid T_{i}>=t_{i}\right]
$$

Assuming that the competing risks are independent, the hazard rate from unemployment is given by:

$$
h_{i}(t)=\sum_{j=1}^{2} h_{i j}(t)
$$

Assuming that all spell observations are independent, the likelihood function for the original state $j$ can be written in terms of hazard rates as follows:

$$
L=\prod_{i=1}^{n}\left[\prod_{j=1}^{2}\left[\frac{h_{i j}(t)}{1-h_{i j}(t)}\right]^{\delta_{i j}}\left[\prod_{k=1}^{t}\left(1-h_{i k}\right)\right]\right]
$$

In this expression, the indicator function $\delta_{i j}$, equals one if the duration is complete (individual $i$ makes a transition to state $j$ ), and equals zero if duration is censored. Therefore, the first component of (3) captures the transition rate and the second component is the survivor function which represents the conditional probability that individual $i$ remains unemployed in period $t$.

Given that (3) is in function of the transition rates, we just need to specify the dependence of the latter on a set of explanatory variables. For the hazard rate we choose the logistic specification that, with multiple events, generates the multinomial logit model (Maddala, 1983). It allows for the three possible states considered: employment through a different employer; employment through recall; and remaining unemployed (which is the reference state category). For individual $i$, the transition rate to state $j$ in period $t$ specified as a multinomial logit can be written as (Steiner, 2001, pp. 96):

$$
h_{j}\left(t \mid z(t), \varepsilon_{j}\right)=\frac{\exp \left(D^{\prime}(t) \alpha_{j}+Z^{\prime}(t) \beta_{j}^{\prime}+\varepsilon_{j}\right)}{1+\sum_{m=1}^{2} \exp \left(D^{\prime}(t) \alpha_{m}+Z^{\prime}(t) \beta_{m}+\varepsilon_{m}\right)}
$$

where $Z(t)$ is a vector of explanatory variables which may vary with time; $\beta$ is the vector of parameters to be estimated; the terms $\alpha$ stands for the baseline hazard which captures the duration

\footnotetext{
${ }^{15}$ According to the simple job search model (Lippman and MacCall, 1976), given a stationary reservation wage, the reemployment probability is the result of two probabilities: the rate at which offers arrive times the probability that a random offer is accepted. In our competing risks model, unemployed workers can either obtain a job through a different employer from the immediately previous one or be re-employed through recall to the previous employer.
} 
dependence. ${ }^{16}$ The specification of the baseline hazard is very important. A common but restrictive approach consists of specifying a parametric form for the baseline hazard. This approach is very strong because the assumptions over the form are difficult to justify from an economic point of view, and provokes a misspecification problem. Instead, we choose a semi-parametric approach (piecewise constant hazard) by specifying monthly dummies $D(t)$ which coefficients for transitions to employment through recall can differ from those for transitions to employment through a different employer. This method presents the advantage of being flexible and assumes that the duration dependence pattern may vary among the states. Finally, since failing to control for unobserved heterogeneity in hazard models tends to create spurious negative duration dependence in the baseline hazard out of unemployment (Lancaster, 1979, 1990), in our analysis $\varepsilon$ accounts for unobserved heterogeneity characteristics in the model such as motivation, ability, effort, family pressure, etc. We assume that the unobserved heterogeneity effect is destination state specific, time constant, and independent of the observed characteristics. ${ }^{17}$

The contribution to the likelihood function for a single individual is equal to (D' Addio and Rosholm, 2005, pp. 454):

$$
L(\beta, \alpha \mid \varepsilon)=\prod_{k=1}^{t} \frac{\exp \left[\left(D_{k}^{\prime} \alpha_{1}+Z_{k}^{\prime} \beta_{1}+\varepsilon_{1}\right) c_{1 k}+\left(D_{k}^{\prime} \alpha_{2}+Z_{k}^{\prime} \beta_{2}+\varepsilon_{2}\right) c_{2 k}\right]}{1+\sum_{m=1}^{2} \exp \left(D_{k}^{\prime} \alpha_{m}+Z_{k}^{\prime} \beta_{m}+\varepsilon_{m}\right)}
$$

where $\mathrm{c}_{\mathrm{jk}}$ are indicators for making the transition to each of the possible destination states at time $\mathrm{k}$; reemployment through a different employer from the immediately previous one $(j=1)$, or reemployment though the same employer as the immediately previous one $(j=2)$. Unemployment spells that are still in progress at the end of the observation period are treated as right censored observations. For these observations, both destination indicators are 0 , and thus, the contribution to the likelihood function is the probability of remaining unemployed for at least the observed sample period. In (5) a common procedure is to specify a parametric distribution for the unobserved heterogeneity such as a normal, gamma distribution, etc. However, given that the unobserved heterogeneity distribution is unknown, Heckman and Singer (1984) have criticised this approach, showing that parametric form assumptions for unobserved heterogeneity might be biased when the chosen distribution for the unobservable term is incorrect. For this reason, they resolve this problem by assuming that unobserved heterogeneity is discretely distributed with unknown support points. Those points can be interpreted as latent individual's types. Then, the likelihood function for an individual may be obtained by integrating the following conditional likelihood distribution:

$$
L(\beta, \alpha, \varepsilon, \pi)=\prod_{s=1}^{S} L(\beta, \alpha \mid \varepsilon=s) \pi(s)
$$

\footnotetext{
16 The explanatory variables used in the analysis are the ones described in Table 1.

17 This is a standard assumption in duration models (D' Addio and Rosholm, 2005; Jenkins, 1995; Rosholm and Svarer, 2001; Steiner, 2001). If this assumption is violated, maximum likelihood estimates will be biased by endogeneity. That is, the estimated $\beta$ coefficients will pick up some of the effects of the unobservable characteristics, $\varepsilon$. If we relax the assumption and $\varepsilon$ is correlated with $\mathrm{Z}$, then the probability of exiting from unemployment through a new job or by recall will be affected, and a test for endogeneity will be required. As proposed by Heckman and Borjas (1980) and Chamberlain (1985), the identification in such models relies in the specification in terms of leads and lags of all the time varying covariates such that their lagged values can be used as instruments for the variables that may be suspected of endogeneity. This is only practical if there is sufficient variation over time in regressors. However, identification of a model where a test for endogeneity could be implemented results infeasible due to the short span of our sample period (see, in this respect, D' Addio and Rosholm, 2005, pp. 454).
} 
Where $\varepsilon$ are the location points (that can be interpreted as intercept for the baseline hazard function), $\pi$ the probability associated to them, and $s$ the number of support points. ${ }^{18}$

Before proceeding with the estimation we have performed some tests for the assumption of 'independence of irrelevant alternatives' (IIA) through the Hausman test (Hausman and McFadden, 1984, HM) and Small Hsiao test (Small and Hsiao, 1985, SH). Those popular tests for testing the validity of IIA consist of partitioning the choice set of alternatives into subsets and therefore comparing the coefficients (HM) or the likelihood functions (SH) from the complete model and from the restricted model obtained by leaving out one or more alternatives. In both tests, results in Table 2 tell us that the null hypothesis of IIA is accepted; therefore, the multinomial logit specification seems to be appropriate for each departure state.

In addition, the results of a Wald test and a LR test are also reported in Table 2. This is done in order to examine the null hypothesis that the coefficients of two categories do not differ significantly from each other, for all the possible combinations. In other words, that some of the alternatives might be combined or aggregated into a simple category, in which case the specification should be binomial rather than a multinomial. In both tests the rejection of the null hypothesis means that it is adequate to distinguish between exits into a new job and into recall. Thus, the multinomial specification for the model seems to be appropriate, since none of the categories should be combined.

\section{Estimation results}

Estimation results are presented in Table 3 for the entire sample (men and women), in Table 4 for men and in Table 5 for women. Two single risk estimations have been obtained based on the likelihood function (6) by the maximum likelihood estimator. The first column reports estimated coefficients for exit from unemployment to a new job and the second column reports estimated coefficients for exit from unemployment through recall. Note that the exponential function of the parameter of a dummy variable measures the hazard rate for an individual with the dummy equal to one relative to the reference person.

Given that both support points are highly significant in all the estimations, exit rates from unemployment to a new job or recall are affected not only by measured individual and job characteristics of the unemployed, but also by their unobserved characteristics. Estimated coefficients and the value of the log-likelihood are affected by the inclusion of unobserved heterogeneity. In particular, unobserved heterogeneity increases the log-likelihood values in the estimations, which indicates an improvement in the fit of the model. ${ }^{19}$

\footnotetext{
${ }^{18}$ It should be indicated that the econometric approach adopted in this article boils down to estimating a reduced form model for employment transitions, conditional on a set of individual and job characteristics and on the worker being in a particular initial state. Other features that make this technique an attractive and flexible one for estimating the effect of those characteristics on the probability of exit from unemployment are: 1) The consideration of competing risks; 2) The incorporation of individual specific unobserved heterogeneity; and 3) The fact that no assumptions are made with respect to the shape of the baseline hazard.

${ }^{19}$ A simple likelihood ratio test of a model with unobserved heterogeneity against another without unobserved heterogeneity confirms the conclusion that unobserved heterogeneity is significant. Thus, the specification with unobservables is identified in the standard multilogit model which is implicit in the text. The value of the likelihood ratio test statistic for the entire sample of a model with unobserved heterogeneity against that without is 203.6. This value exceeds the critical chi square value of 3.84 for $1 \mathrm{~d}$.f. at significance level of $5 \%$ and therefore, unobserved heterogeneity component should be included in the specification of the model. The values of the likelihood ratio test statistic are 47.94 and 118.56 for males and females, respectively. Both values exceeds the critical chi square value (previously mentioned); therefore, unobserved heterogeneity is also significant in those models.
} 
Table 2

Specification tests

Test for IIA

$x^{2}\left(\mathrm{P}>x^{2}\right)$

Ho: Odds(Outcome-J vs Outcome-K) are independent of other alternatives.

Hausman

Omitted: Different employment.

$62.652(0.69)$

Omitted: Recall job.

$-18.983(1.00)$

Small-Hsiao

Omitted: Different employment

$62.661(0.69)$

Omitted: Recall job.

$62.298(0.70)$

Wald and LR test for combining outcomes

Ho: All coefficients except intercepts associated with given pair of outcomes are 0

(i.e., categories can be collapsed).

Wald test

Combining different employment and recall job.

$2905.035(0.00)$

Combining diff. employment and unemployment.

2632.265(0.00)

Combining recall job and unemployment.

4058.603(0.00)

LR test

Combining different employment and recall job.

3308.793(0.00)

Combining diff. employment and unemployment.

$2807.516(0.00)$

Combining recall job and unemployment.

$4371.359(0.00)$

According to results in Table 3, men are more likely than women to exit from unemployment through a new job. The estimated coefficient translates into a probability differential of 44.8 per cent. On the other hand, men are 7.7 per cent less likely than women to be recalled to the previous employer. This implies that women tend to enjoy shorter unemployment duration than men when they return to the previous employer. However, it takes women longer than men to find a new job.

As regards age, the 35-39 age interval marks the difference: the younger workers are more likely to find a new job while elder workers are more likely to be recalled. This result for age on the recall hazard rate is most probably related to the fact that older workers have more firmspecific human capital, which is an attribute highly valued by the employer. In addition, it is a fact that younger workers are more willing to move from jobs (and employers) for improving their job match and eventually settling in a more stable career path (Jensen and Svarer, 2003).

Our data set does not contain variables related to the individual's educational attainment or occupation. However, it provides information related to the required level of qualification for the job (see Table A.1 of the Appendix). This allows us to find that workers holding jobs that require higher qualification levels are more likely to be recalled by their previous employer. On the other hand, lower qualified workers suffer the greatest difficulties in finding a new job. This result, combined with that associated with age, fits quite nicely into a variety of theories suggesting that the accumulation of firm-specific human capital by older workers, the job-shopping behaviour of younger workers, and the level of qualifications are well explanatory factors of the ways and probabilities of escaping unemployment for recalled workers (Fischer and Pichelmann, 1991).

One important variable that provides interesting insights into the way workers exit unemployment in Spain is firm size. Two relevant factors are associated with firm size: the effectiveness of workers' representatives and the cost of layoffs to the firm. In Spain, firms can have two types of workers' representatives: the unions (secciones sindicales) and the workers councils (comités de empresa). Given that the latter are internal bodies formed by employees of the firm, their existence and effectiveness depend on firm size. In particular, workers councils can only exist in firms with at least fifty employees, and have gained increasing prestige among 
Table 3

Estimates and standard error of transitions from unemployment to employment through recall or to employment through a different employer after controlling observed and unobserved heterogeneity (with two support points)

\section{ENTIRE SAMPLE}

Gender (male 1)

Age 16-19

Age 20-24

Age 25-29

Age 30-34

Age 35-39

Age 40-44

Age 45-49

Age 50-54

Age 55-59

Age 59-62

\begin{tabular}{lllllll} 
Dif. Emp & & & & \multicolumn{2}{l}{ Recall } & \\
\cline { 1 - 1 } Coef. & S.E. & Sign. & & Coef. & S.E. & Sign. \\
0.370 & 0.024 & $* * *$ & & -0.080 & 0.028 & $* * *$
\end{tabular}

Qualification level:

Qual. High

Qual. Med.-High

Qual. Medium-Low

Qual. Low

$\begin{array}{rrrrrr}0.352 & 0.051 & * * * & -0.545 & 0.068 & * * * \\ 0.422 & 0.040 & * * * & -0.268 & 0.047 & * * * \\ 0.271 & 0.039 & * * * & -0.212 & 0.046 & * * * \\ 0.138 & 0.043 & * * * & -0.109 & 0.047 & * * * \\ & & & & & \\ -0.060 & 0.049 & & 0.137 & 0.051 & * * * \\ -0.106 & 0.055 & * * & 0.139 & 0.056 & * * * \\ -0.098 & 0.062 & & 0.162 & 0.063 & * * * \\ -0.062 & 0.080 & & 0.151 & 0.081 & * * * \\ -0.453 & 0.178 & * * * & 0.401 & 0.155 & * \\ & & & & & \\ -0.010 & 0.051 & & 0.212 & 0.059 & * * * \\ & & & & & \\ 0.086 & 0.037 & * * * & 0.060 & 0.048 & \\ -0.165 & 0.037 & * * * & -0.043 & 0.045 & \end{array}$

Type of contract:

Permanent contract

Permanent per task

Temporary

Other type

$\begin{array}{rrr}-0.306 & 0.094 & * * * \\ 0.187 & 0.045 & * * * \\ 0.050 & 0.070 & \end{array}$

$\begin{array}{lll}1.692 & 0.086 & * * * \\ 0.731 & 0.070 & * * * \\ 0.904 & 0.088 & * * *\end{array}$

Firm size:

$<10$ employees

$>10$ and $<50$ employees

$>50$ and $<200$ employees

$>200$ and $<1000$ employees

$>1000$ employees

$\begin{array}{rrllll}0.054 & 0.027 & * * & 0.192 & 0.033 & * * * \\ 0.151 & 0.032 & * * * & 0.393 & 0.039 & * * * \\ 0.061 & 0.040 & & 0.517 & 0.046 & * * * \\ -0.025 & 0.058 & & 0.804 & 0.060 & * * *\end{array}$

Tenure in previous job:

$<4$ weeks

$>4$ weeks and $<20$ weeks

$>20$ weeks and $<1$ year

$>1$ year and $<2$ years

$>2$ years

Worked in a Temporary Help Agency

$\begin{array}{lllrrl}0.473 & 0.033 & * * * & 0.081 & 0.037 & * * \\ 0.602 & 0.039 & * * * & 0.552 & 0.041 & * * * \\ 0.611 & 0.050 & * * * & 0.134 & 0.066 & * * \\ 0.593 & 0.059 & * * * & -0.245 & 0.095 & * * * \\ 0.408 & 0.055 & * * * & -0.061 & 0.072 & \end{array}$

Unemployment benefit status:

Receives no benefits

Contributory benefits

Assistance benefits

\begin{tabular}{rrlrrl}
-0.400 & 0.041 & $* * *$ & -0.566 & -0.058 & $* * *$ \\
-0.454 & 0.055 & $* * *$ & -0.873 & 0.070 & $* * *$ \\
-0.016 & 0.008 & $*$ & -0.032 & 0.015 & $* * *$ \\
0.102 & 0.007 & $* * *$ & 0.125 & 0.007 & $* * *$ \\
\hline
\end{tabular}

Month * Contributory benefits

Number of previous jobs 


\begin{tabular}{|c|c|c|c|c|c|c|}
\hline & \multicolumn{3}{|c|}{ Dif. Emp } & \multicolumn{3}{|l|}{ Recall } \\
\hline & Coef. & S.E. & Sign. & Coef. & S.E. & Sign. \\
\hline \multicolumn{7}{|l|}{ Unemployment benefit status: } \\
\hline Regional Unemployment rate (tvc) & -0.023 & 0.009 & $* * *$ & -0.062 & 0.010 & $* * *$ \\
\hline \multicolumn{7}{|l|}{ Sector of activity: } \\
\hline \multicolumn{7}{|l|}{ Industry } \\
\hline Agriculture & 0.510 & 0.153 & $* * *$ & -0.004 & 0.186 & \\
\hline Construction & 0.056 & 0.041 & & -0.341 & 0.051 & $* * *$ \\
\hline Services & 0.009 & 0.034 & & -0.249 & 0.040 & $* * *$ \\
\hline \multicolumn{7}{|l|}{ Mass points and probability: } \\
\hline$\varepsilon_{1}($ s.e. $)$ & \multicolumn{6}{|c|}{$-4.908(0.243)^{* * *}$} \\
\hline$\varepsilon_{2}$ (s.e.) & \multicolumn{6}{|c|}{$-3.020(0.125)^{* * *}$} \\
\hline $\operatorname{Pr}\left(\varepsilon_{1}\right)$ & \multicolumn{6}{|c|}{0.096} \\
\hline $\operatorname{Pr}\left(\varepsilon_{2}\right)$ & \multicolumn{6}{|l|}{0.904} \\
\hline No. Observations & \multicolumn{6}{|l|}{125,044} \\
\hline No. of individuals & \multicolumn{6}{|l|}{23,035} \\
\hline Log-likelihood & \multicolumn{6}{|l|}{$-68,259$} \\
\hline
\end{tabular}

Note: Regression includes controls for 17 regions, unemployment duration (in months) dummies variables (baseline) and month of entering unemployment. "tvc" means time varying covariate. Source: Social security data base, except for the the regional unemployment rate, which has been obtained from the Spanish Labour Force Survey, EPA *** Indicates significance at 1 per cent; ${ }^{*}$ indicates significance at 5 per cent.

workers since the early $1980 \mathrm{~s} .{ }^{20}$ In larger firms, therefore, the relevant legislative constraints that determine the size and effectiveness of the workers councils are considerably more restrictive with respect to the optimising behaviour of firms (Mavromaras and Rudolph, 1998). Given the costs borne by workers in recalls -in terms of losses in current income, future benefit entitlements and employment security - councils are expected to effectively minimize layoff durations in larger firms. Moreover, smaller firms can be expected to experience longer recall durations because individual workers employed by smaller firms will be less able to influence the timing of such recall. As firm size increases, there will be more and stronger workers councils with both the power and the incentive to intervene and assist workers' optimising behaviour. Our results are consistent with these predictions, for we find that the hazard rate of exiting from unemployment through recall increases with firm size. For instance, compared to firms with less than 10 employees, the recall hazard rate is 21 per cent higher in firms between 10 and 50 employees and 67 per cent higher in those with 200-1000 employees.

As seasonal downturns in demand and production are easily anticipated by employers, they may turn to temporary layoffs as an employment adjustment strategy. This expected relationship between seasonal work and temporary layoff unemployment is captured in our regressions through the variable type of contract. In particular, the observation that temporary layoff unemployment serves to accommodate seasonal fluctuations in production is confirmed by the estimated coefficients for the temporary contract, and, especially, for the permanent per task contract. Workers under this latter type of contracts enjoy strong links with their previous

\footnotetext{
${ }^{20}$ The available evidence show greater importance of workers councils as workers representatives along time (Jimeno and Toharia, 1993; Malo, 2005).
} 
Table 4

Men's transitions from unemployment to employment through recall or to different employer with unobserved heterogeneity (two support points)

MEN

\begin{tabular}{|c|c|c|c|c|c|}
\hline Dif. E & & & Recal & & \\
\hline Coef. & S.E. & Sign. & Coef. & S.E. & Sign. \\
\hline
\end{tabular}

Age at unemployment spell:

Age 16-19

Age 20-24

Age 25-29

Age 30-34

Age 35-39

Age 40-44

Age 45-49

Age 50-54

Age 55-59

Age 59-62

$\begin{array}{llllll}0.182 & 0.067 & * * * & -0.708 & 0.097 & * * * \\ 0.332 & 0.056 & * * * & -0.212 & 0.070 & * * * \\ 0.197 & 0.055 & * * * & -0.206 & 0.069 & * * * \\ 0.172 & 0.058 & * * * & -0.108 & 0.071 & * * *\end{array}$

$\begin{array}{rllll}-0.076 & 0.065 & & 0.034 & 0.076 \\ -0.175 & 0.071 & * * & 0.024 & 0.083 \\ -0.092 & 0.080 & & 0.084 & 0.094 \\ 0.009 & 0.098 & & 0.004 & 0.119 \\ -0.382 & 0.198 & * * & 0.275 & 0.210\end{array}$

Qualification level:

Qual. High

$-0.101-0.075$

0.235

0.094

Qual. Med.-High

Qual. Medium-Low

Qual. Low

$\begin{array}{rrrrr}0.111 & 0.057 & * * & 0.082 & 0.076 \\ -0.080 & 0.055 & & -0.108 & 0.073\end{array}$

Type of contract:

Permanent contract

Permanent per task

Temporary

Other type

$\begin{array}{rr}-0.428 & 0.165 \\ 0.141 & 0.063 \\ 0.041 & 0.104\end{array}$

$* * *$
$* *$

1.997

0.145

0.832

0.104

0.750

0.144

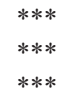

Firm size:

$<10$ employees

$>10$ and $<50$ employees

$>50$ and $<200$ employees

$\begin{array}{lll}0.095 & 0.036 & * * * \\ 0.192 & 0.044 & * * * \\ 0.038 & 0.056 & \end{array}$

0.145

0.047

$\begin{array}{ll}0.228 & 0.059\end{array}$

$0.392 \quad 0.070$

$>200$ and $<1000$ employees

$-0.043$

0.089

0.719

0.101

Tenure In previous job:

$<4$ weeks

$>4$ weeks and $<20$ weeks

$\begin{array}{lllrl}0.501 & 0.043 & * * * & 0.023 & 0.054 \\ 0.640 & 0.049 & * * * & 0.470 & 0.058 \\ 0.661 & 0.066 & * * * & 0.253 & 0.090 \\ 0.578 & 0.079 & * * * & -0.066 & 0.124 \\ 0.435 & 0.079 & * * * & 0.014 & 0.107\end{array}$

$>20$ weeks and $<1$ year

$>1$ year and $<2$ years

$>2$ years

0.435

0.079

0.066

0.107

Unemployment benefit status:

Receives no benefits

Contributory benefits

Assistance benefits

\begin{tabular}{rrrrrrr} 
& -0.418 & 0.054 & $* * *$ & -0.682 & 0.084 & $* * *$ \\
& -0.425 & 0.077 & $* * *$ & -0.989 & 0.121 & $* * *$ \\
& -0.023 & 0.012 & $* *$ & -0.034 & 0.021 & \\
& 0.083 & 0.009 & $* * *$ & 0.099 & 0.010 & $* * *$ \\
& 0.027 & 0.012 & $* * *$ & -0.080 & 0.014 & $* * *$ \\
\hline
\end{tabular}

Month * Contributory benefits

Number of previous jobs

Regional Unemployment rate (tvc) 
MEN

\begin{tabular}{|c|c|c|c|c|c|c|}
\hline & \multicolumn{3}{|c|}{ Dif. Emp } & \multicolumn{3}{|l|}{ Recall } \\
\hline & Coef. & S.E. & Sign. & Coef. & S.E. & Sign. \\
\hline \multicolumn{7}{|l|}{ Sector of activity: } \\
\hline \multicolumn{7}{|l|}{ Industry } \\
\hline Agriculture & 0.348 & 0.185 & $*$ & 0.049 & -0.257 & \\
\hline Construction & 0.061 & 0.049 & & -0.276 & 0.066 & $* * *$ \\
\hline Services & -0.082 & 0.046 & $*$ & -0.246 & 0.059 & $* * *$ \\
\hline \multicolumn{7}{|c|}{ Mass points and probability: } \\
\hline$\varepsilon_{1}$ (s.e.) & \multicolumn{6}{|c|}{$-4.575(0.316)^{* * *}$} \\
\hline$\varepsilon_{2}$ (s.e.) & \multicolumn{6}{|c|}{$-2.668(0.192) * * *$} \\
\hline $\operatorname{Pr}\left(\varepsilon_{1}\right)$ & \multicolumn{6}{|c|}{0.107} \\
\hline $\operatorname{Pr}\left(\varepsilon_{2}\right)$ & \multicolumn{6}{|l|}{0.893} \\
\hline No. Observations & \multicolumn{6}{|c|}{62,136} \\
\hline Log-likelihood & \multicolumn{6}{|c|}{$-34,961.853$} \\
\hline
\end{tabular}

Note: See note Table 3.

employer when they are out of work. This relationship is much stronger than with other types of contracts, since individuals retain seniority and other employment-related benefits (for instance, they have the right to return to the same job with the same employer, since they have the privilege of being requested first by their previous employer on their availability to re-enter their payroll ${ }^{21}$ ). Given that workers with such contracts are treated as if they had maintained their employment relationship, they usually do not engage in job-seeking activities because they regard themselves as employed and they are virtually certain to return to their jobs at the end of the layoff period.

There are several other variables that provide interesting insights into the way workers exit from unemployment in Spain. In particular, the worker's previous employment history might be an important explanatory factor of the reemployment probability. In this sense, individuals more accustomed to move from jobs are supposedly more "employable", and thus are expected to leave unemployment earlier. This expectation is confirmed in results obtained for the variable which measures the number of previous jobs: individuals subject to higher turnover (in terms of the number of previous jobs held) enjoy a higher escape rate from unemployment. Moreover, having worked via a THA enhances 50.4 per cent the probability of finding a new job, while the recall hazard is not affected by agency work. Compared to individuals who worked in the industry sector, those who worked in construction or services are significantly less likely to be recalled. Moreover, tenure in the previous job appears to be an important variable for explaining the exit rate from unemployment. A job that lasted 4 weeks or less is the circumstance that makes it harder for workers to exit from unemployment by finding a new job. Having held a job that lasted more than two years makes it the hardest to exit unemployment by being recalled to the previous employer.

The worker's unemployment benefit status is included in the regression as dummies that indicate whether or not the individual receives contributory or assistance benefits. Regardless of the type of exit, these two dummies obtain the expected negative sign: non-claimants exit from unemployment faster than claimants do. Although the disincentive effect of contributory and assistance benefits is similar in magnitude for unemployed who make a transition to a new job, the impact of each type of

\footnotetext{
${ }^{21}$ In addition, when being laid-off, those individuals receive payments subsidized by the Government (through the UI system for the time not worked).
} 
Table 5

Women's transitions from unemployment to employment through recall or to different employer with unobserved heterogeneity (two support points)

WOMEN

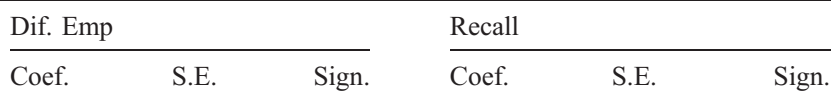

Age at unemployment spell:

Age 16-19

Age 20-24

Age 25-29

Age 30-34

Age 35-39

Age 40-44

Age 45-49

Age 50-54

Age 55-59

Age 59-62

$\begin{array}{rr}0.568 & 0.084 \\ 0.527 & 0.061 \\ 0.366 & 0.061 \\ 0.124 & 0.067 \\ -0.036 & 0.081 \\ 0.003 & 0.091 \\ -0.113 & 0.110 \\ -0.263 & 0.156 \\ -0.831 & 0.462\end{array}$

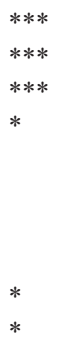

$-0.368$

0.100

$-0.287$

0.065

$-0.207$

0.064

$-0.108$

0.066

$-0.218$

0.211

0.072

0.224

0.081

0.270

0.091

0.505

0.119

0.249

Qualification level:

Qual. High

Qual. Med.-High

Qual. Medium-Low

Qual. Low

$\begin{array}{rrrrrr}0.106 & 0.073 & * & 0.206 & 0.079 & * * * \\ 0.038 & 0.054 & * & -0.012 & -0.065 & * \\ -0.220 & 0.054 & * * * & -0.046 & 0.060 & *\end{array}$

Type of contract:

Permanent contract

Permanent per task

Temporary

Other type

$\begin{array}{rr}-0.196 & 0.124 \\ 0.265 & 0.070 \\ 0.065 & 0.104\end{array}$

1.463

0.634

0.877

$\begin{array}{ll}0.114 & * * * \\ 0.095 & * * * \\ 0.117 & * * *\end{array}$

Firm size:

$<10$ employees

$>10$ and $<50$ employees

$\begin{array}{rr}0.006 & 0.044 \\ 0.103 & 0.049 \\ 0.081 & 0.058 \\ -0.035 & 0.078\end{array}$

0.229

0.512

0.625

0.882

$\begin{array}{ll}0.050 & * * * \\ 0.054 & * * * \\ 0.062 & * * * \\ 0.078 & * * *\end{array}$

Tenure In previous job:

$<4$ weeks

$>4$ weeks and $<20$ weeks

$\begin{array}{ll}0.423 & 0.048 \\ 0.571 & 0.055 \\ 0.564 & 0.078 \\ 0.626 & 0.098 \\ 0.445 & 0.081\end{array}$

$$
\begin{aligned}
& * * * \\
& * * * \\
& * * * \\
& * * * \\
& * * *
\end{aligned}
$$

0.103

0.052

0.603

0.057

$-0.014$

0.100

$>2$ years

0.626
0.445

$-0.468$

0.154

Worked in a Temporary Help Agency

$-0.065$

0.102

Unemployment benefit status:

Receives no benefits

Contributory benefits

Assistance benefits

Month * Contributory benefits

Number of previous jobs

Regional Unemployment rate (tvc)

$\begin{array}{rrlr}-0.395 & 0.065 & * * * & -0.475 \\ -0.509 & 0.081 & * * * & -0.838 \\ -0.021 & 0.012 & * & -0.042 \\ 0.145 & 0.012 & * * * & 0.173 \\ 0.030 & 0.013 & * * & -0.049\end{array}$

\begin{tabular}{ll}
0.081 & $* * *$ \\
0.088 & $* * *$ \\
0.021 & $* *$ \\
0.012 & $* * *$ \\
0.014 & $* * *$ \\
\hline
\end{tabular}


WOMEN

\begin{tabular}{|c|c|c|c|c|c|c|}
\hline & \multicolumn{3}{|c|}{ Dif. Emp } & \multicolumn{3}{|l|}{ Recall } \\
\hline & Coef. & S.E. & Sign. & Coef. & S.E. & Sign. \\
\hline \multicolumn{7}{|l|}{ Sector of activity: } \\
\hline Agriculture & 0.844 & 0.279 & $* * *$ & -0.174 & -0.281 & \\
\hline Construction & -0.453 & 0.105 & $* * *$ & -0.677 & 0.102 & $* * *$ \\
\hline Services & 0.118 & 0.057 & $* *$ & -0.313 & 0.058 & $* * *$ \\
\hline \multicolumn{7}{|c|}{ Mass points and probability: } \\
\hline$\varepsilon_{1}$ (s.e.) & \multicolumn{6}{|c|}{$-4.773(0.209) * * *$} \\
\hline$\varepsilon_{2}$ (s.e.) & \multicolumn{6}{|c|}{$-2.918(0.173)^{* * *}$} \\
\hline $\operatorname{Pr}\left(\varepsilon_{1}\right)$ & \multicolumn{6}{|c|}{0.152} \\
\hline $\operatorname{Pr}\left(\varepsilon_{2}\right)$ & \multicolumn{6}{|l|}{0.848} \\
\hline No. Observations & \multicolumn{6}{|l|}{62,908} \\
\hline Log-likelihood & \multicolumn{6}{|c|}{$-33,047.64$} \\
\hline
\end{tabular}

Note: See note Table 3.

benefit differs in magnitude among workers who were recalled. Compared to workers who do not receive benefits, those who receive assistance (contributory) benefits are 58 (33) per cent less likely to be recalled. Assistance benefit is typically received by workers with low worker-firm attachment. Thus, this result is consistent with the existence of implicit contracts between firms and UI recipients: workers with above-average attachment are recalled faster by the firm that laid them off.

Since the Spanish unemployment insurance system provides benefits for a limited time and in a declining fashion, we have included in the specification an interaction term between receipt of contributory benefits and months of unemployment. This allows us to capture possible variation of the coefficient on the dummy for unemployment benefit status along the unemployment spell. We obtain that the disincentive effect of benefits falls with duration of unemployment. Therefore, the unemployed worker usually suffers liquidity constraints and becomes less selective about job opportunities as their spells of unemployment lengthen (Katz and Meyer, 1990; Van den Berg, 1990; Narendranathan et. al., 1993; Dormont et al., 2001; Jenkins and García-Serrano, 2004).

Regional labour market conditions are controlled for in the regression by including each region's quarterly unemployment rate as a time varying covariate. Also, regional dummies are included (not reported). As expected, a higher regional unemployment rate is associated with a lower exit rate from unemployment. This negative impact of the regional unemployment rate on the exit rate is stronger for the recall alternative. However, regional dummies are still quite significant. The use of recall seems to be more common in Andalusia and Extremadura, which are regions with unemployment rates above the national average.

We now consider the issue of duration dependence of the hazard rates that result from estimating the competing risks model for the two alternatives of leaving unemployment. Fig. 1 shows the estimated hazard rate, after controlling for unobserved heterogeneity, at mean of covariates for the entire sample. Because we already know that the unemployment hazard rate through recall is lower than the unemployment hazard rate into a new job, we are interested here in the shape of theses hazards. The predicted hazards that result from the estimation of our competing risks model exhibit quite different shapes. We could say that apart from drops in moths 4th, 7th and 14th, the recall hazard rate exhibits no duration dependence. On the other hand, the estimated hazard for exit into a new job is virtually flat until the 10th month, and presents positive duration dependence thereafter. 


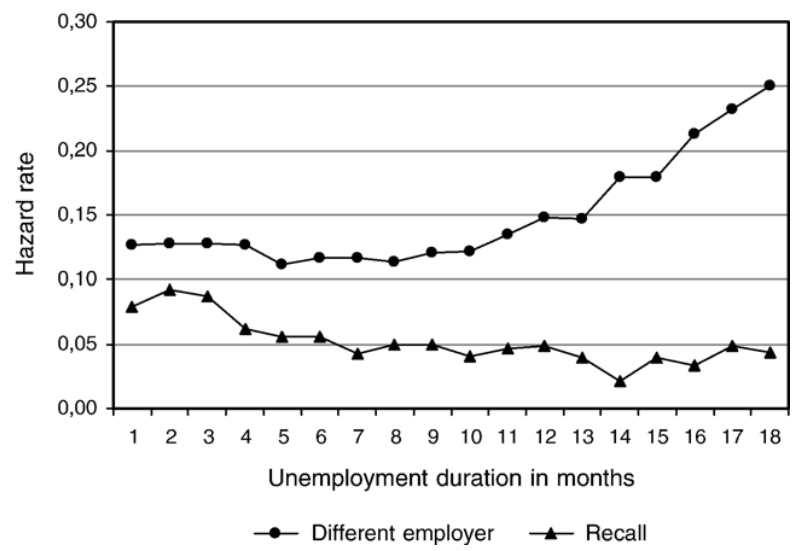

Fig. 1. The shape of the estimated hazard rate from unemployment into recall or different employer (after controlling unobserved heterogeneity) at the mean of covariates.

In essence, at short unemployment durations, profiles are rather similar for both types of exits; however, for long unemployment durations, the estimated new-job hazard is clearly upward slopping whereas the recall hazard levels off. This reflects the fact that in the beginning of the unemployment spell, workers expected to be recalled do little search for a new job. Since firms cannot immediately determine whether downturns are transitory or permanent, the longer a low demand state lasts, the more likely it will become a "permanent" low demand state. As a consequence, the longer a worker remains on layoff, the lower his perceived instantaneous recall probability. This will induce a declining reservation wage. Thus, revised expectations of the recall probability result in increased search activity, which increases the new job hazard rate. These results are quite consistent with expectations arising from both contract and search models (Mavromaras and Orme, 2004, pp. 52). An additional interpretation can be given from the demand-side of the labour market: as the employer's option of reemploying workers on temporary layoff weakens with unemployment duration, he/she will try to recall workers as earlier as possible (Katz, 1986; Katz and Meyer, 1990), that is, as soon as demand conditions are again favourable.

Fig. 2 shows the estimated duration dependence for UI and UA recipients separately. This figure shows the estimated hazard rate (after controlling for unobserved heterogeneity) at mean of covariates for UI and UA recipients. We observe that the new job hazard rates are above the estimated recall hazard rates for both types of recipients. Nevertheless, the UI hazard rates (for both new and recall jobs) are larger than those of UA recipients. Thus, expected unemployment duration of UA recipients is larger than that of UI recipients. Notice that the mobility pattern of both recipients for each outcome is similar to that in Fig. 1, since hazard rates are evaluated at mean of covariates. Thus, the recall hazard rate basically exhibits no duration-dependence, while the estimated hazard for new jobs presents no duration-dependence up to the 10th month and positive duration dependence thereafter.

Having also estimated separate models for men and women, we present the results in Tables 4 and 5, respectively. Some noteworthy differences are observed in the impact of some independent variables according to gender. As regards age, we find that women follow a pattern similar to that of the entire sample: compared to the 30-39 age group, younger women are much more likely to find a new job and elder women are more likely to be recalled. However, only men below 30 years-old are clearly different from the others in that they appear much less likely to be recalled. Both men and women 


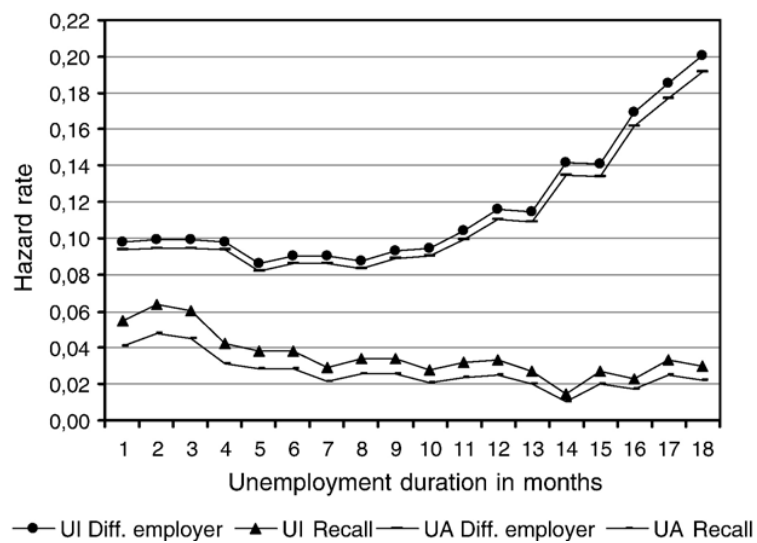

Fig. 2. The shape of the estimated hazard rate from unemployment into recall or different employer (after controlling unobserved heterogeneity) at the mean of covariates, by type of benefit recipients.

experiment a positive impact on the likelihood of being recalled from the fact of holding a high qualification level, but only the latter suffer a negative impact on finding a new job from holding a low qualification level. Estimated results by gender as regards the remainder explanatory variables (type of contract, tenure in the previous job, firm size, employed via a THA, unemployment benefit status and number of previous jobs) do not substantially differ from those obtained for the entire sample.

Finally, Fig. 3 shows the pattern of duration dependence by gender (after controlling for unobserved heterogeneity) at mean of covariates. As previously discussed for the entire sample, the hazard rate from unemployment into a new job keeps over the hazard rate from unemployment through recall. Furthermore, the recall hazard rate (which is larger for females) exhibits no duration dependence, while the estimated hazard for new jobs (which is larger for males) presents positive duration dependence.

\section{Summary and conclusions}

In this paper we have analysed transitions out of unemployment in Spain. We have considered two alternative ways of becoming employed: recall by the previous employer or reemployment in a new job. The data set used has been generated by combining Social Security and unemployment benefit records produced by the Spanish Employment Office. It contains information about worker job characteristics before and after the unemployment begins, as well as the dates of start and end of every spell of employment from June 1999 to June 2002. Using these rich data, we have estimated a discretetime duration model with competing risks of exits to a recall or a new job. In such model, duration dependence is accounted for through the use of a semi-parametric piecewise constant hazard estimation, and unobserved heterogeneity is taken into account. This is the first article that addresses the study of transitions out of unemployment (via recall or new job) using the referred data and methodology for Spain.

The coefficients obtained by variables related to personal characteristics indicate that the probability of being recalled is higher for women, older people and for higher qualified persons (who are presumably in possession of larger specific human capital). Concerning job characteristics, workers are more likely to be recalled in the following cases: 1) held a permanent per task or fixedterm contract; 2) stayed in the previous job between 20 weeks and 1 year; 3 ) their job was in the 


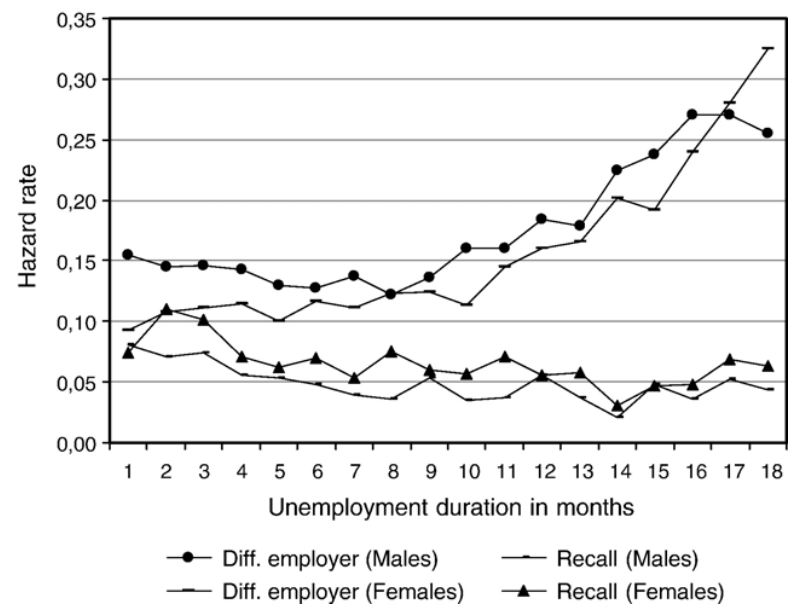

Fig. 3. The shape of the estimated hazard rate from unemployment into recall or different employer (after controlling unobserved heterogeneity) at the mean of covariates, by gender.

industry sector; 4) were employed by a large firm. In contrast, men, young workers (below 35 yearsold) and those working via a temporary help agency enjoy a higher likelihood of exiting from unemployment into a new job. We also find a positive influence of previous employment experiences on future new jobs: the longer the job stability experienced by workers in previous employment engagements, the higher the exit rate from unemployment into a new job.

Another important result is that not only do individual and job characteristics influence the hazard rates differently, but also that the duration dependence is different according to the route of exiting unemployment. The recall hazard rate basically exhibits no duration dependence, while the estimated hazard for new jobs shows no duration dependence until the 10th month and positive duration dependence, thereafter. Finally, as regards the effect of contributory and assistance benefits, non-claimants exit from unemployment faster than claimants do. Nevertheless, while the disincentive effect of the two types of benefits is similar in magnitude for the unemployed who entered into a new job, the negative effect for recall workers is stronger for those holding assistance benefits rather than contributory benefits.

The empirical findings in this paper establish that recall to the former employer and, therefore, temporary job separations constitute an important feature of the Spanish labour market. Therefore, to adequately investigate transitions out of unemployment in Spain we need to consider the recall outcome. It also helps to understand the nature of unemployment itself. Lack of experience rating and demand fluctuations provide strong incentives for implicit contracts. The pervasive use of fixed-term contracts is a reflection of those incentives. When a fixed-term contract ends (as opposed to a permanent contract), often no particular cost arises for the employer, and the Spanish Public Employment System has no means of determining whether non-renewal of the contract has the character of likely recall in the future. In this setting, unemployment benefit entitlements, therefore, may create incentives for employers to offer fixed-term rather than permanent contracts, and to play with the recall probability. A labour market reform that pursues the reduction of temporary employment in Spain needs to make sequential contracting of the same workers less attractive, for both the employer and the worker.

Moreover, our results are also relevant for the design of active labour market policies. It is clear that the public employment service must consider workers waiting to be recalled lees needed of 
employment services, particularly job search assistance. This will reduce the dead weight generally associated with active labour market measures. However, workers who fail to fulfil their expectation of recall could have trouble leaving unemployment if they have made no effort to find a new job. This possibility needs also to be considered.

Given the empirical findings in this paper, there is a risk that UI benefits will artificially subsidise the regular use of temporary layoffs. That is, possibly collusive behaviour for taking advantage of the unemployment compensation system may make implicit contracts of this sort attractive for both workers and firms. In essence, benefit administrators need to assess the frequency of benefit claimants associated with temporary layoffs that seem to have no real insurance function, and the effectiveness of measures to limit them. These issues remain open for future research.

\section{Appendix A}

Table A.1

Occupation category groups

\begin{tabular}{ll}
\hline Occupation category groups & National job category levels \\
\hline High Occupation & 1. Engineers and graduates. \\
& 2. Technical engineers and other skilled workers. \\
& 3. Chief and departmental heads. \\
\hline Upper-Intermediate Occupation & 4. Other semi-skilled workers. \\
& 5. Skilled clerks. \\
Lower-Intermediate Occupation & 6. Auxiliary workers. \\
\hline Low Occupation & 7. Semi-skilled clerks. \\
& 8. Skilled labourers. \\
\hline
\end{tabular}

Table A.2

Loss of observations from initial data set

Initial sample size:

Observations deleted due to:

Enter into unemployment due to reasons different from involuntary ones

Missing variables used in the empirical analysis:

Sex

Sector of activity

Qualification

Age

Reason for benefits

Replacement ratio

Enjoy unemployment benefit different from contributive or assistance ones

Unemployment duration $<30$ days

Final sample size used in the empirical analysis:

\section{References}

Alba-Ramirez, A., 1998. Re-employment Probabilities of Young Workers in Spain. Investigaciones Económicas 22 (2), 201224.

Allison, P.A., 1982. Discrete-Time Methods for the Analysis of Event Histories. In: Leinhardt, S. (Ed.), Sociological Methodology. Jossey-Bass Publishers, San Francisco, pp. 6198. 
Arranz, J.M., Muro, J., 2004. Recurrent Unemployment, Welfare Benefits and Heterogeneity. International Review of Applied Economics 18 (4), 423441.

Baily, M.N., 1977. On the Theory of Layoffs and Unemployment. Econometrica 45, 10431063.

Cebrián, I., García, C., Muro, J., Toharia, L., Villagómez, E., 1996. The Influence of Unemployment Benefits on Unemployment Duration: Evidence from Spain. Labour 10, 239267.

Chamberlain, G., 1985. Panel Data. In: Griliches, S., Intriligator, M. (Eds.), Handbook of Econometrics. North-Holland, Amsterdam, pp. 12471318.

Clark, Kim B., Summers, L.H., 1979. Labor Market Dynamics and Unemployment: A Reconsideration. Brookings Papers on Economic Activity 1, 3060.

Corak, M., 1996. Unemployment Insurance, Temporary Layoffs and Recall Expectations. Canadian Economic Observer, Statistics Canada (11), 3.1 3.15 (May).

D' Addio, A.C., Rosholm, M., 2005. Exits from Temporary Jobs in Europe: A competing risks Analysis. Labour Economics 12, 449468.

Dormont, B., Fougère, D., Prieto, A., 2001. L'effet de l'allocation unique dégressive sur la reprise d'emploi. Economie et Statistiques 343, 328.

Emerson, M., 1988. Regulation or Deregulation of the Labor Market. European Economic Review 32 (4), 775817.

Feldstein, M.S., 1975. The Importance of Temporary Layoffs: An Empirical Analysis. Brookings Papers on Economic Activity 3, 725744 .

Feldstein, M.S., 1976. Temporary Layoffs in the Theory of Unemployment. Journal of Political Economy 84, 937957.

Feldstein, M.S., 1978. The Effect of Unemployment Insurance on Temporary Layoff Unemployment. The American Economic Review 65, 834846.

Fischer, G., Pichelmann, K., 1991. Temporary Layoff Unemployment in Austria: Empirical Evidence from Administrative Data. Applied Economics 23, 14471452.

García-Fontes, W., Hopenhayn, H., 1996. Flexibilización y Volatilidad del Empleo. Moneda y Crédito 202, 205227.

García-Pérez, J.I., 1997. Las Tasas de Salida del Empleo y el Desempleo en España (1978-1993). Investigaciones Económicas 21, 2953.

García-Pérez, J.I., Muñoz-Bullón, F., 2005a. Are Temporary Help Agencies Changing Mobility Patterns in the Spanish Labour Market? Spanish Economic Review 7 (1), 4365.

García-Pérez, J.I., Muñoz-Bullón, F., 2005b. Temporary Help Agencies and Occupational Mobility. Oxford Bulletin of Economics and Statistics 67, 163180.

Gutierrez-Rieger, H., Podzeczeck, K., 1981. On the Non-existence of Temporary Layoff Unemployment in Austria. Empirica 2, 277289.

Hausman, J.A., McFadden, D., 1984. Specification Tests for the Multinomial Logit Model. Econometrica 52 (2), 12191240.

Heckman, J.J., Borjas, G., 1980. Does Unemployment Cause Future Unemployment? Definitions, Questions and Answers from a Continuos Time Model for Heterogeneity and State Dependence. Economica 47, 247283.

Heckman, J.J., Singer, B., 1984. A Method for Minimising the Impact of Distributional Assumptions in Econometric Models for Duration Data. Econometrica 52, 272320.

Jenkins, S., 1995. Easy Estimation Methods for Discrete Time Duration Models. Oxford Bulletin of Economics and Statistics 57 (1), 120138.

Jenkins, S.P., García-Serrano, C., 2004. The Relationship Between Unemployment Benefits and Re-employment Probabilities: Evidence from Spain. Oxford Bulletin of Economics and Statistics 66 (2), 239260.

Jensen, P., Nielsen, M.S., 1999. Short- and Long-Term Unemployment: How Do Temporary Layoffs Affect this Distinction? Working Paper 99-06, Centre for Labour Market and Social Research, Aarhus.

Jensen, P., Svarer, M., 2003. Short-and Long-Term Unemployment: How Do Temporary Layoffs Affect this Distinction? Empirical Economics 28, 3344.

Jensen, P., Westergärd-Nielsen, N., 1990. Temporary Layoffs. In: Hartog, J. (Ed.), Panel Data and Labor Market Studies. North-Holland, Amsterdam.

Jimeno, J.F., Toharia, L., 1993. Spanish Labour Markets: Institutions and Outcomes. In: Hartog, J., Theeuwes, J. (Eds.), Labour Market Contracts and Institutions. Elsevier Science Publishers, pp. 299322.

Katz, L.F., 1986. Layoffs, Recall and the Duration of Unemployment. NBER Working Paper, vol. 1825. January.

Katz, L.F., Meyer, B.D., 1990. The Impact of the Potential Duration of Unemployment Benefits on the Duration of Unemployment. Journal of Public Economics 41, 4572.

Lancaster, T., 1979. Econometric Methods for the Analysis of Duration Data. Econometrica 47, 939956.

Lancaster, T., 1990. The Econometric Analysis of Transition Data. Cambridge University Press, Cambridge.

Lauer, C., 2003. Education and Unemployment: A French-German Comparison. Discussion Paper 03-34, ZEW. 
Lippman, S.A., MacCall, J.J., 1976. The Economics of Job Search: A Survey. Economic Inquiry 14, 155367.

Maddala, G.S., 1983. Limited-dependent and Qualitative Variables in Econometrics. Cambridge University Press, Cambridge.

Malo, M.A., 2005. A Political Economy Model of Workers' Representation: The Case of Union Elections in Spain. European Journal of Law and Economics 19, 115134.

Mavromaras, K.G., Orme, C.D., 2004. Temporary Layoffs and Split Population Models. Journal of Applied Econometrics $19,4967$.

Mavromaras, K.G., Rudolph, H., 1998. Temporary Separations and Firm Size in the German Labour Market. Oxford Bulletin of Economics and Statistics 60 (2), 215226.

Mortensen, D.T., 1990. A Structural Model of Unemployment Insurance Benefit Effects on the Incidence and Duration of Unemployment. In: Weiss, Y., Fishelson, G. (Eds.), Advances in the Theory and Measurement of Unemployment. Macmillan, London.

Moy, J., Sorrentino, C., 1981. Unemployment, Labor Force Trends, and Layoff Practices in 10 Countries. Monthly Labor Review 313 (December).

Narendranathan, W., Stewart, M., 1993. How Does the Benefit Effect Vary as Unemployment Spells Lengthens? Journal of Applied Econometrics 8, 361381.

OECD, 2002. OECD Employment Outlook. Paris.

Robertson, M., 1989. Temporary Layoffs and Unemployment in Canada. Industrial Relations 28, 8390.

Røed, K., Nordberg, M., 2003. Temporary Layoffs and the Duration of Unemployment. Labour Economics 10, 381398.

Rosholm, M., Svarer, M., 2001. Structurally Dependent Competing Risks. Disctussion Paper No. 265, IZA.

Small, K.A., Hsiao, C., 1985. Multinomial Logit Specification Tests. International Economic Review 26 (3), 619627.

Steiner, V., 2001. Unemployment Persistence in the West German Labor Market: Negative Duration Dependence or Sorting? Oxford Bulletin of Economics and Statistics 63, 91113.

Van den Berg, G., 1990. Nonstationarity in Job Search Theory. The Review of Economics Studies 57, 255277.

Winter-Ebmer, R., 1998. Potential Unemployment Benefit Duration and Spell Length: Lessons from a Quasi-Experiment in Austria. Oxford Bulletin of Economics and Statistics 60, 3345. 